\title{
Editorial
}

\section{Problem Based Learning in Rajshahi Medical College}

\section{A R M Saifuddin Ekram ${ }^{1}$, M Mamun Ur Rashid ${ }^{2}$, S M Akram Hossain ${ }^{3}$, M Fazlur Rahman ${ }^{4}$}

Problem Based Learning is a curriculum development and delivery system that recognizes the need to develop problem solving skills as well as the necessity of helping students to acquire necessary knowledge and skills. It was first developed in Mc Master University, Canada in 1970 's, which is used currently in more than $80 \%$ of medical schools across the United States \& Canada. PBL utilizes real world problems, not hypothetical case studies with neat and convergent outcomes. It is in the process of struggling with actual problems that students learn both content and critical thinking skills. ${ }^{1,2}$

Our traditional teaching is teacher centered, where teachers play the active role and students are mere passive learners. As problem based learning (PBL) is a process where problem is utilized as a stimulus, the students get ample opportunity to learn by themselves through self- learning. Here, teachers act as facilitators. If we could introduce PBL, the learning process will obviously be effective for learners, which are essential to develop the expertise of the students of medical science to serve the community at the grass - root level of this country. In 2004-2005 a pilot study was done in Rajshahi Medical College in collaboration with Center for Medical Education, Dhaka and WHO to observe whether we can incorporate PBL and organ / system-based integration in undergraduate medical teaching learning.
Knowledge, attitude and practice (KAP) study was done before and after the PBL sessions among the students and teachers. Analysis of KAP study showed most of the students did not know anything about PBL as a teaching method in prestudy period but in post-study phase most of the students showed positive attitude towards PBL as a method of teaching. Results of the teachers KAP study were almost same as that of the student but a bit more conservative.

It is important to keep in mind the principle objectives of the PBL method - the acquisition of an extensive, integrated knowledge base that is readily recalled and applied to the analysis and care of patient problems. The development of effective and efficient PBL method requires: problem-solving or clinical reasoning skills, clinical skills, self-directed learning skills and team skills.

As the students in a problem-based learning curriculum work with a problem they should be able to identify what they need to learn and what resources they are going to use to accomplish that learning. Problem-based learning is not teachercentered, the teacher does not direct what students should learn or what resources they should use. Instead the teacher designs and provides the problem simulations and patient experiences that challenge the students to learn what is needed in their preparation for a career in medicine. Problem-based learning should not occur within a

1 Professor (C.C.), Department of Medicine, Rajshahi Medical College, Rajshahi.

2 Professor (C.C.), Department of Pharmacology, Rajshahi Medical College, Rajshahi.

3 Professor, Department of Anatomy, Rajshahi Medical College, Rajshahi.

${ }^{4}$ Professor, Department of Pathology, Rajshahi Medical College, Rajshahi. 
single discipline or subject. Information should be integrated from the many disciplines that are basic to the practice of medicine such as: anatomy, biochemistry, clinical medicine, epidemiology, ethics, human behavior, immunology, pathology, pharmacology, physiology, psychology etc. During self-directed learning, students should be able to access, study and integrate information from all the disciplines that might be related to understanding and resolving the particular problem they are working with just as the physician must recall and apply information integrated from these diverse sources in patient work. So collaboration is essential. ${ }^{3,4,5}$

The ability to accurately monitor the adequacy of personal performance is essential to developing life-long self-directed study skills. The ability to provide colleagues with accurate feedback is an important skill in medical practice. The opportunity to develop effective clinical skills must be embedded within the problem-based learning curriculum. Many of the problems in the curriculum can be presented as standardized or simulated patients allowing the development of these skills along with problem-solving, selfdirected study and team skills. In addition, recurrent opportunities should be provided for students to work in clinical settings applying what they have learned in their problem work to real patients and developing their clinical skills. ${ }^{3}$

Problem-based learning should not be episodic, added on to or mixed in with more traditional, didactic, teacher-directed, passive, memorizationbased and lecture-based educational methods. Problem-based learning requires that students are active learners, responsible for their own learning and have adequate time for self-directed learning. The contrasting and conflicting curricular and time demands of didactic teacher directed learning diminishes the value of problem-based learning and confuses and frustrates both teachers and students. It prevents full realization of the value of problem-based learning and the excitement and enjoyment the method can provide students preparing for a career in medicine. It must be an independent curricular undertaking. So it is said that a more accurate title of PBL might be "student-centered, problem-based, inquiry-based, integrated, collaborative, reiterative learning." 3,5,6,7

As PBL might be better described as "studentcentered, problem-based, inquiry-based, integrated, collaborative, reiterative, learning”, it is doubtful whether we can introduce and maintain it in our curriculum in the present setting. Partial introduction of PBL without assessment and giving appropriate weight in examination will not bring the fruitful result. So before introducing it fully we have to prepare our students and ourselves so that we can hold it, practice it and can improve our quality of health care delivery system, which needs much time and preparatory exercise.

\section{References}

1. Stepien W J, Gallagher S A. "Problem-based Learning: As Authentic as it Gets." Educational Leadership. 1993; 50(7) 25-8 .

2. Gallagher S, Rosenthal H., Stepien W."The Effects of Problem-Based Learning on Problem Solving. Gifted Child Quarterly.1992; 36(4), 195-200.

3. The Minimal Essentials For Problem-Based Learning In Medical Education. http://www.pbli.org/pbl/pbl_essentials.html.

4. Pross H. Problem-Based Learning Student/ Tutor Handbook.. http://meds.queensu.ca/medicine/pbl/ pblhome.htm.

5. Problem Based Learning At Samford University. http://www.samford.edu/pbl/definitions.html.

6. Maudsley G. Roles and responsibilities of the problem based learning tutor in the undergraduate medical curriculum, BMJ 1999 ; 318: 657- 661

7. Albanese M. Problem-based learning: why curricula are likely to show little effect on knowledge and clinical skills. Medical Education 2000;34: 729- 738 